\title{
Article
}

\section{Laser 3D Printing of Inorganic Free-Form Micro-Optics}

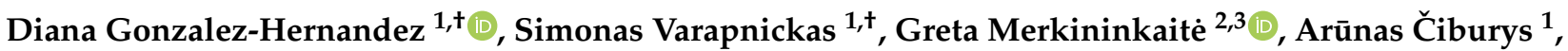

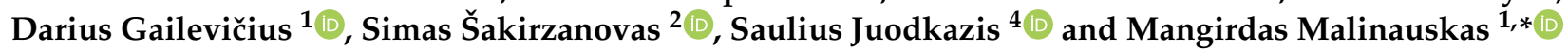 \\ 1 Laser Research Center, Physics Faculty, Vilnius University, LT-10223 Vilnius, Lithuania; \\ dianalauragzzhdz@gmail.com (D.G.-H.); simonas.varapnickas@ff.vu.lt (S.V.); arunas.ciburys@ff.vu.lt (A.Č.); \\ darius.gailevicius@ff.vu.lt (D.G.) \\ 2 Faculty of Chemistry and Geoscience, Vilnius University, LT-03225 Vilnius, Lithuania; \\ greta.merkininkaite@chgf.vu.lt (G.M.); simas.sakirzanovas@chf.vu.lt (S.Š.) \\ Femtika, LT-10224 Vilnius, Lithuania \\ 4 Optical Sciences Center and ARC Training Centre in Surface Engineering for Advanced Materials (SEAM), \\ Faculty of Science, Engineering and Technology, Swinburne University of Technology, \\ Hawthorn 3122, Australia; saulius.juodkazis@gmail.com \\ * Correspondence: mangirdas.malinauskas@ff.vu.lt \\ + These authors contributed equally to this work.
}

Citation: Gonzalez-Hernandez, D.; Varapnickas, S.; Merkininkaitè, G.; Čiburys, A.; Gailevičius, D.; Šakirzanovas, S.; Juodkazis, S.; Malinauskas, M. Laser 3D Printing of Inorganic Free-Form Micro-Optics. Photonics 2021, 8, 577. https:// doi.org/10.3390/photonics 8120577

Received: 8 November 2021 Accepted: 2 December 2021 Published: 14 December 2021

Publisher's Note: MDPI stays neutral with regard to jurisdictional claims in published maps and institutional affiliations.

Copyright: (c) 2021 by the authors. Licensee MDPI, Basel, Switzerland. This article is an open access article distributed under the terms and conditions of the Creative Commons Attribution (CC BY) license (https:/ / creativecommons.org/licenses/by/ $4.0 /)$.

\begin{abstract}
A pilot study on laser 3D printing of inorganic free-form micro-optics is experimentally validated. Ultrafast laser direct-write (LDW) nanolithography is employed for structuring hybrid organic-inorganic material SZ2080 ${ }^{\mathrm{TM}}$ followed by high-temperature calcination post-processing. The combination allows the production of $3 \mathrm{D}$ architectures and the heat-treatment results in converting the material to inorganic substances. The produced miniature optical elements are characterized and their optical performance is demonstrated. Finally, the concept is validated for manufacturing compound optical components such as stacked lenses. This is an opening for new directions and applications of laser-made micro-optics under harsh conditions such as high intensity radiation, temperature, acidic environment, pressure variations, which include open space, astrophotonics, and remote sensing.
\end{abstract}

Keywords: laser 3D nanolithography; micro-optics; astrophotonics; 3D printing; additive manufacturing; SZ2080 ${ }^{\mathrm{TM}}$; hybrid materials; inorganics; imaging; high temperature

\section{Introduction}

Ultrafast laser written photonic circuits in transparent materials is a steadily growing scientific field and approaching towards practical implementations [1]. The laser directwrite (LDW) technique based on ultrashort pulses allows prototyping of dense hierarchical integrated devices of organic photopolymers [2] as well manufacturing of ultra highperformance devices made in diamond [3]. Both mentioned examples are incredible achievements individually; however, a cross-road of whether choosing the CAD-CAM design freedom for a prototype or the functional materials with limited processing options is inevitable. Here, we employ our developed laser additive manufacturing technique of $\mathrm{Si} / \mathrm{ZrO}_{2}$ tunable inorganic 3D micro-/nano-structures [4]. The approach combines a method of laser-assisted precision additive manufacturing and an advanced thermal post-processing solution. The laser direct writing 3D lithography enabled by non-linear light-matter interaction [5] is already a well-established technique for routine fabrication of diverse organic [6] and hybrid or composite materials [7]. However, until now, it was quite limited for direct processing of transparent inorganics of ceramic and crystalline phases [8]. On the other hand, the current advances of the technique are driven vastly by the rapid progress for implementation in manufacturing of various micro-optical and nano-photonic monolith elements as well as fully assembled complex 3D components [9-13]. Thus, here we demonstrate the combination of ultrafast laser 3D nanolithography and thermal posttreatment for opening a route for production of free-form inorganic structures-specifically 
free-form micro-optics. Up to now, it was just partially realized and restricted to limitations such as: 2D/2.5D structures [14], or millimeter-scale dimensions [15,16], or non-transparent components [17]. It is intuitively obvious and clearly anticipated that the Laser Induced Damage Threshold (LIDT) of such inorganic optical components will be of higher values preferable in practical micro-optics [18] and nano-photonic applications [19], especially taking into account high-temperature or light-intensity, chemically harsh environments, and heavy duty applications [20]. Another wide area of applications of calcinated microoptical elements is in specialized spectral applications, e.g., in astro-photonics where UV transparent micro-optical elements are required for coupling light into optical fibers [21]. Currently, such micro-optical elements can be made by laser ablation of UV-transparent sapphire [22]; however, a better optical quality of surfaces and unmatched freedom in 3D sculpting is achievable only via calcination.

The aim of the work was validation of the concept that transparent in the visible range and free-form micro-optics of inorganic materials can be made via a straightforward combination of laser 3D printing and high-temperature calcination. The implemented workflow is graphically shown in Figure 1.

a)

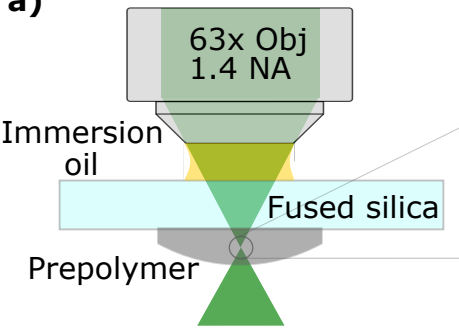

c)

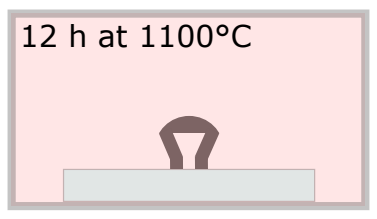

e)

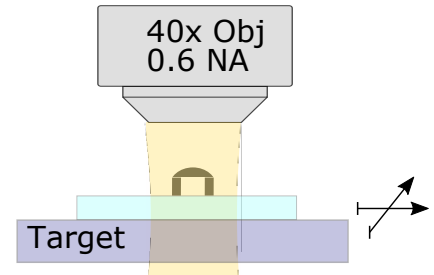

Light source b)
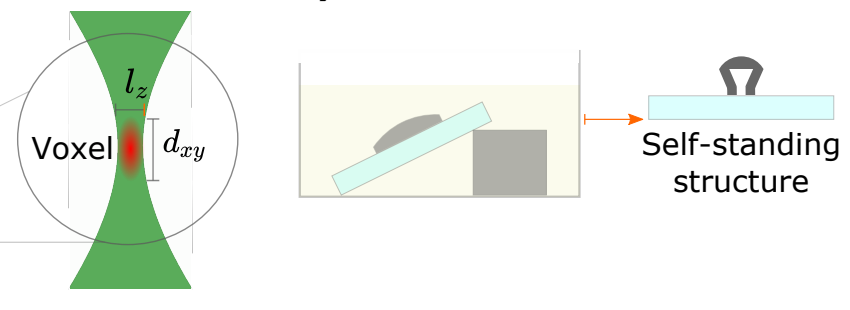

d)

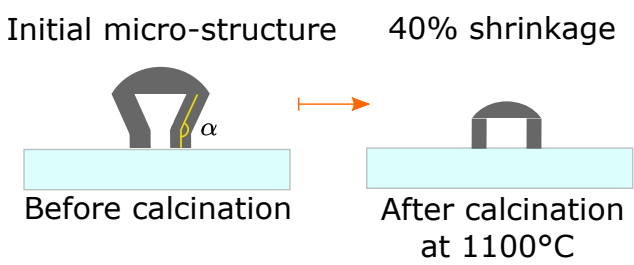

f)

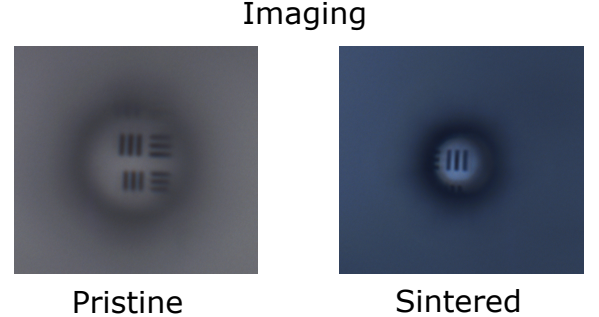

Figure 1. Schematics of the proposed approach: (a) LDW process; (b) wet chemical development bath (placing the sample with an angle results in a cleaner development process reducing the polymer waste); (c) calcination process; (d) a geometrical comparison of micro-optical structure prior and post calcination, a pre-compensation angle of the legs is shown as well as an expected shrinkage; (e) optical performance characterization of the micro-structure prior and post calcination; (f) imaging and measuring the resolving power by a calibration test target.

In order to achieve this goal, a series of micro-optical components were fabricated, calcinated and characterized geometrically as their functional performance was validated. The obtained glass-ceramic 3D micro-lenses demonstrated sufficiently high optical transmittance, imaging and magnification. Altogether, this proves it as a novel and feasible way to produce various micro-optical components with a high-degree of freedom in geometry. Additionally, stacking of individual elements into a compound monolith optical components was benchmarked-proving its feasibility for making custom integrated optical 
micro-systems. Further studies are projected towards precise evaluation of their refractive index $(n)$ and even potentially tuning it towards specific demands.

\section{Materials and Methods}

\subsection{Used Materials}

We used the hybrid organic-inorganic material SZ2080 ${ }^{\mathrm{TM}}$ (IESL-FORTH, Heraklion, Greece) with $1 \mathrm{wt} \%$ concentration of Irgacure 369 [23]. The specific photopolymer was chosen due to its superior structuring and fabricated object physical performance, known and tunable chemical composition, and proven compatibility with the calcination process [4]. A drop drying technique was used for the preparation of the sample. The sol-gel prepolymer solution was drop-casted on a fused silica substrate, which is used due to its high melting temperature. A heating process on a hot plate was implemented to dry the sol-gel prepolymer drop by the following temperature stages sequence: (1) $5 \mathrm{~min}$ from room temperature to $40^{\circ} \mathrm{C}$ leaving the sample to stay for $10 \mathrm{~min},(2) 5 \mathrm{~min}$ from the previous temperature to reach $70{ }^{\circ} \mathrm{C}$ staying for $10 \mathrm{~min}$ and (3) $5 \mathrm{~min}$ to reach $90{ }^{\circ} \mathrm{C}$ from the previous temperature staying for $40 \mathrm{~min}$. By this method, the temperature gradually increases to ensure the prepolymer acquires a uniform hard gel form to be used for the fabrication of the desired micro-optical structure. The samples were developed overnight in a chemical bath of 4-methyl-2-pentanone after the LDW fabrication process to remove nonpolymerized material and leave the self-standing structures attached to the surface of the glass substrate. An optimization of the development process of the micro-structure from the flat standard is shown in Figure $1 \mathrm{~b}$ with an inclination of the sample during the chemical development. The presented method for developing ensures a reduction in the polymer waste on the final sample. The sample was later left to dry at room temperature in ambient conditions prior to further examination.

\subsection{Geometry}

The 3D micro-structures were designed to consist of two main parts: the micro-lens itself and its supports. The micro-lenses were formed by concentric circles, which allowed a high control over the fabrication parameter, i.e., the fabrication light intensity at the center of the lens, to avoid burning and defects, as shown in Figure 2a. We designed a $50 \mu \mathrm{m}$ of diameter micro-lens with $65 \mu \mathrm{m}$ radius and $5 \mu \mathrm{m}$ height, where such characteristics are shown in Figure $2 b$.

The supports are formed by two main parts: bottom straight and top bent sections. A raster scanning was used for fabrication of the supports with faster scanning speed and higher intensity since the resulting surface quality was not relevant and only enough rigidity for mechanical stability was required. Three different arbitrary selected compensation angles were implemented in the bent section of the supports of the micro-lenses: $0^{\circ}, 16^{\circ}$ and $26^{\circ}$. Figure $2 \mathrm{c}$ shows a preliminary view of the design of micro-lenses and the difference in the supports' angle chosen to pre-compensate for the bending of the supports due to an up to $70 \%$ expected shrinkage (reduction by a factor of $\approx 1.4$ ) of the micro-structure after the calcination process.

\subsection{Employed Equipment}

The principle employed laser fabrication equipment, and the production procedure was sequentially described in detail previously [24]. The micro-lenses were fabricated by 3D LDW by photo-exposing the prepolymer using the second harmonic femtosecond beam ( $\lambda$ centered at $515 \mathrm{~nm}$ ) of a $\mathrm{Yb}: \mathrm{KGW}$ laser with a pulse duration of $300 \mathrm{fs}$ and repetition rate of $200 \mathrm{kHz}$. The beam was focused into the prepolymer drop by a Zeiss $63 \times 1.4 \mathrm{NA}$ microscope objective under the oil immersion method with Immersol $518 \mathrm{~F}$, as shown in Figure 1a. The fabrication intensity $\left(I_{0}\right)$ was in the order of $0.23 \mathrm{TW} / \mathrm{cm}^{2}$ with an approximate $10 \%$ reduction in intensity $I_{\mathcal{c}}=0.9 I_{0}$ at the center of the micro-lens to avoid burning and defects. The supports were fabricated at a higher raster scanning speed and applied exposure intensity, $500 \mu \mathrm{m} / \mathrm{s}$ and $0.37 \mathrm{TW} / \mathrm{cm}^{2}$, for a more rapid fabrication. They 
consisted of straight and tilted parts in order to match the pre-compensation angle $\alpha$, as shown in Figure 2c.

The polymerization was confined due to thresholded non-linear (multi-photon) absorption. Some linear absorption, avalanche ionization and thermal effects could contribute to the fabrication too. Despite that, the technique is compatible with the typical LDW twophoton polymerization setups employing ultrafast lasers.

a)

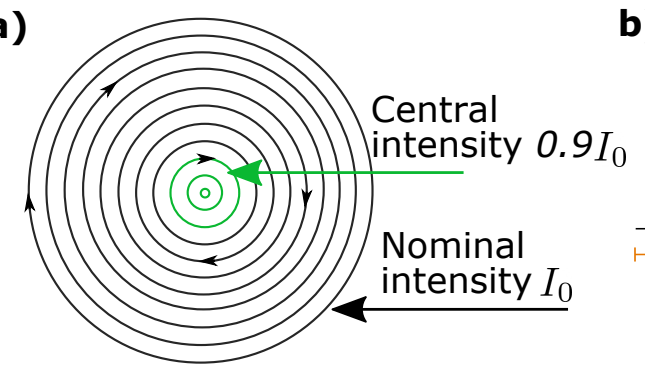

b)

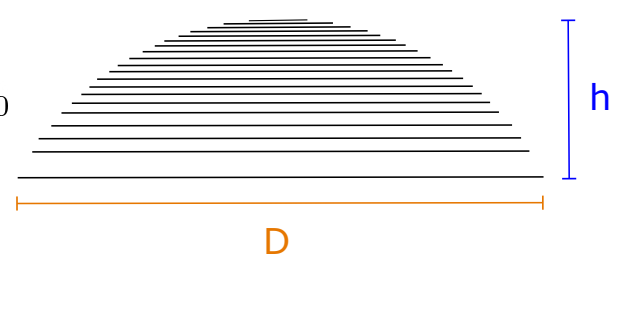

c)

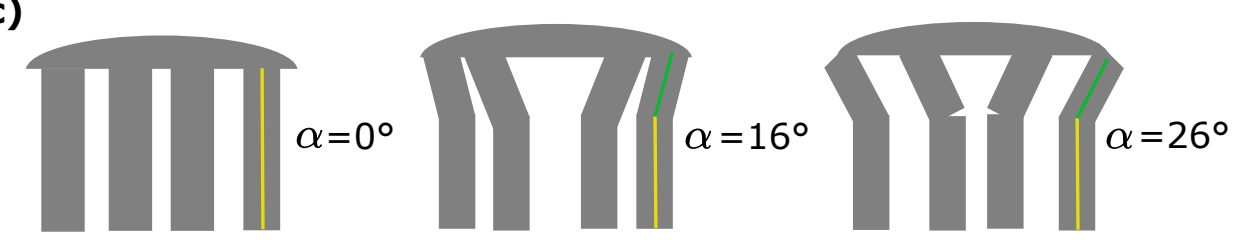

Figure 2. Fabrication strategy characteristics: (a) Top view of micro-lens fabricated by concentric circles with tunable intensity (within the central part of the scanning, a 10\% decrease in nominal value $I_{0}$ was applied); (b) schematic of micro-lens design parameters; (c) micro-structure design: supports: consisting of two parts (marked in yellow straight and green color for the tilted part) to adjust the pre-compensation angle $\alpha$ of the micro-lens support.

\subsection{Calcination}

In order to convert the laser 3D fabricated organic-inorganic micro-optics, the calcination process was applied: a heat-treatment was performed at $1100{ }^{\circ} \mathrm{C}$ to remove the organic components, as was applied for diverse architectures $[4,8]$. The calcination process was performed in a high-temperature Nabertherm oven, raising the temperature for $12 \mathrm{~h}$ until reaching $1100^{\circ} \mathrm{C}$ and maintaining it for $3 \mathrm{~h}$. A cooling curve was designed to slowly decrease the heating of the sample, from $1100^{\circ} \mathrm{C}$ to room temperature. The specific temperature was empirically found as $1000^{\circ} \mathrm{C}$ does not always result in transparent phases, while $1200{ }^{\circ} \mathrm{C}$ might already induce some undesired melting and loss of shape. This was not studied systematically while performing this study, yet the knowledge was obtained carrying out manufacturing experiments and is published in detail elsewhere $[4,8]$. Though, in principle, all photopolymers will experience shrinkage while sintering, only hybrid ones enable conversion into inorganic substance phases. In comparison, the $\mathrm{SZ2080}{ }^{\mathrm{TM}}$ hybrid was shown as superior for quality structure production with respect to OrmoComp ${ }^{\circledR}$ [25].

\subsection{Optical and Scanning Electron Microscopy Characterization}

The initial characterization was made using an optical microscope (OM) to confirm the survival from the development of the micro-objects. Then the physical dimensions and the surface quality of the micro-optical structures were performed using a Scanning Electron Microscope (SEM, Hitachi TM-1000 (Tokyo, Japan) and Thermo Scientific Quanta 250 (Agawam, MA, USA), where no metallic coating was applied.

\subsection{Performance Evaluation}

The optical performance was obtained, judging the resolving power of the microlenses before and after the calcination process using the optical microscope for imaging purposes. A target unit Thorlabs R3L1S4P-Positive 1951 USAF provided the resolution 
lines to obtain the corresponding resolving power of the micro-lenses. The micro-lenses were placed directly over the target unit and manually aligned to different lines groups to perform their imaging using the transmission mode of the optical microscope (illuminating with a bright field white light). By translating the cover-slip where the micro-structures were standing, as shown in Figure 1e, it is possible to image the group lines from the target unit and obtain the resolving power of the micro-lenses in both stages of the experiment, as presented in Figure 1f: prior, and post calcination to compare any change in their optical performance. The same equipment and methodology was employed for assessing the $n$-the distance of the micro-lens and its focal plane were measured by translating it with stages, then recalculated ("reverse engineered") to the corresponding value for the exact shape of the produced micro-lenses.

\section{Results}

We have used light intensity at the sample as the key irradiation parameter determining the non-reversible light-matter interaction, since the photo modification occurs only when and where a certain light intensity level is reached. The Intensity-(I), which takes into account the measured average laser optical power $-P$, optical systems' including objective transmittance $-T$, pulse repetition rate $-R$, nominal beam waste radius $-w_{0}$, and single pulse duration $-\tau$ can be expressed in the following:

$$
I=\frac{2 P T}{R w_{0}^{2} \pi \tau} .
$$

More specifics and details regarding laser exposure parameters including polymerization and optical damage intensity threshold behavior can be found in the recent review topic covering spatio-temporally confined light and its initiated physical-chemical polymerization mechanisms [5]. Based on this sole parameter, the light processing conditions can be significantly easier reproduced while employing various pulsed laser sources with different average powers, pulse durations, repetition rates and energies, exposure doses and durations.

The microstructures were fabricated using a concentric circle scanning method with an intensity of $0.23 \mathrm{TW} / \mathrm{cm}^{2}$. This scanning method presents the advantage of high control of the fabrication parameters allowing to reduce $10 \%$ of the intensity at the center, which proved to avoid burning at the center of the micro-lens and defects, which affect their optical performance. The SEM images' prior calcination in the upper row of Figure 3 shows the three different arbitrary angles that were chosen to study as the pre-compensation supports' angles.

The obtained resolving power of the calcinated micro-lenses was determined to be $4.39 \mu \mathrm{m}$ (line size) or $228 \mathrm{lp} / \mathrm{mm}$ based on line group 7 item 6 in a positive 1951 USAF target, as shown in Figure 4. The value is close to the ones recently reported in the literature. Again, one should note that the calcinated micro-lenses are of sub-100 $\mu \mathrm{m}$ dimensions and made out of inorganic glass material with respect to $\mathrm{mm}$-scaled lenses reported elsewhere [12,26].

The dimensions of the fabricated micro-structures were retrieved by two different methods. The diameter $(D)$ of the thin spherical micro-lenses was obtained by an analysis of the top view of images taken by an optical microscope in transmission mode and compared with the side view of SEM images of the structures, both analyzed using ImageJ [27] software. Table 1 shows the comparison of size for the optical microscope and SEM images prior to and post the calcination process. The diameter of the micro-lenses shows the repeatability of the fabrication with results of $50 \pm 1.5 \mu \mathrm{m}$. The results after calcination at $1100{ }^{\circ} \mathrm{C}$ show the shrinkage of the structures by around $40 \%$. No fissure of the structures was observed within the breadth of the carried experiments. The fracture of structures could potentially emerge in the case that they would be fully attached to the substrate and form larger areas in contact with non-shrinking substrate, which would induce stress accumulation. However, the support structures ensure isotropic shrinkage without fragmentation or delamination of the volumes/surfaces. 

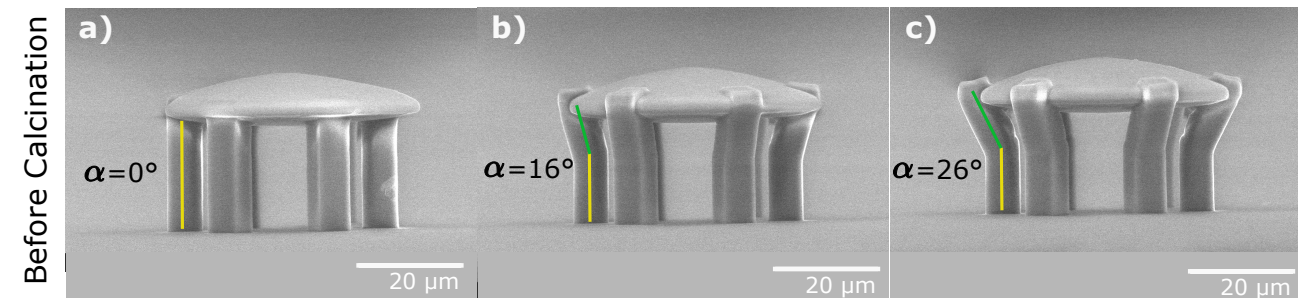

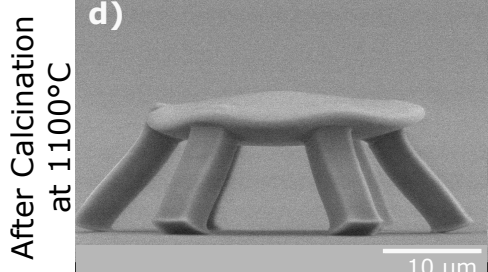

d) e)

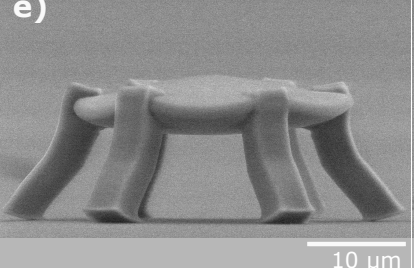

f)

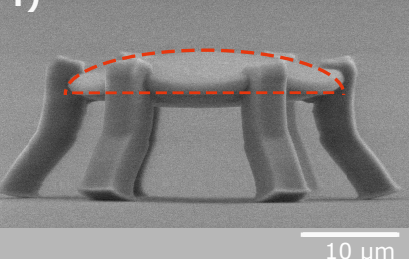

Figure 3. Shrinkage and shape pre-compensation of calcinated micro-optics. The first row shows the initial shape of micro-lenses of $50 \mu \mathrm{m}$ diameter prior calcination with support angles of (a) $0^{\circ}$, (b) $16^{\circ}$ and (c) $26^{\circ}$. The bottom row (d-f) shows the same microstructures after calcination at $1100{ }^{\circ} \mathrm{C}$. In (f), the arrows indicate the preserved shape of the lens despite the overall structure, mainly the legs, being partially distorted. However, the central part of the volume is still lens-like and thus performs as a micro-optical component (demonstrated in Figure 4).

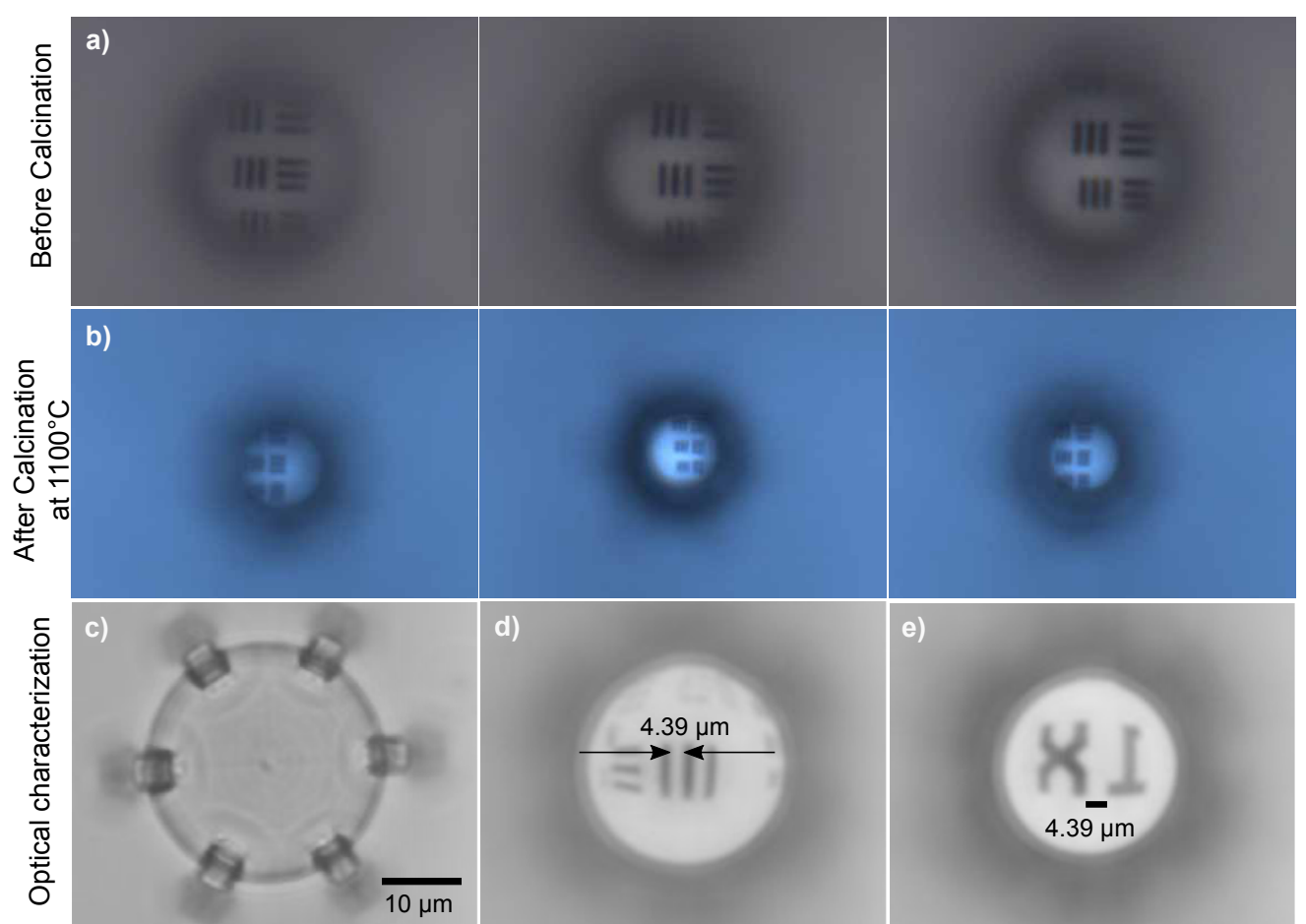

Figure 4. Optical performance of the produced micro-lenses. The top (a) row shows the imaging of a target prior to calcination while the middle row (b) shows the imaging after calcination. Bottom row: (c) Optical image of the calcinated structure. All lenses presented a resolving power of $4.39 \mu \mathrm{m}$ (228 lp/mm group 7 item 6 in the 1951 USAF target). (d) Image of the lines of the target and, (e) image of a "X1" characters performed by a calcinated transparent micro-lens. 
Table 1. The micro-lenses geometrical and focusing characteristics. The micro-structures were fabricated with the same dimensions over three different support structures, measured using SEM before and after calcination. The values of diameters were retrieved by a side view of the micro-lenses, as shown in Figure 3, and the focal distance was measured as visualized in Figure 1. The shrinkage ratio and averaged values were calculated accordingly.

\begin{tabular}{ccccc}
\hline Micro-Structure & Before & After & Shrinkage & Focal Distance \\
\hline Supports at $0^{\circ}$ & $49.3 \mu \mathrm{m}$ & $28.6 \mu \mathrm{m}$ & $42 \%$ & $40.4 \mu \mathrm{m}$ \\
Supports at $16^{\circ}$ & $49.0 \mu \mathrm{m}$ & $28.8 \mu \mathrm{m}$ & $41.3 \%$ & $38.0 \mu \mathrm{m}$ \\
Supports at $26^{\circ}$ & $48.5 \mu \mathrm{m}$ & $28.5 \mu \mathrm{m}$ & $41.3 \%$ & $37.7 \mu \mathrm{m}$ \\
Average & $48.9 \pm 0.5 \mu \mathrm{m}$ & $28.6 \pm 0.5 \mu \mathrm{m}$ & $42.7 \pm 1.5 \%$ & $38.7 \pm 1.7 \mu \mathrm{m}$ \\
\hline
\end{tabular}

Within the limitation of the employed techniques and equipment in the current study, we could not obtain the precise shape of the lenses and measure the exact focal distance in order to confidently estimate $n$. The preliminary measuring using illumination with a bright field white light indicated an averaged value of $\approx 1.609$, which is reasonable but needs to be assessed using alternative method(s) for confirmation. However, due to densification of the material during calcination, it is expected to increase as it was observed for the glass preparation out of $\mathrm{ZrO}_{2}-\mathrm{SiO}_{2}$ sol-gels. Namely for the $\mathrm{SZ}_{2} 080^{\mathrm{TM}}$-like material, it can be up to $n=1.617$, as previously reported for non-structured material in Reference [28].

\section{Discussion}

\subsection{Thermal Effects of the Hybrid Organic-Inorganic Material SZ2080 ${ }^{T M}$}

Recent works showed that one of the best ways to achieve high quality free-form 3D manufacturing of inorganic materials is combining LDW and thermal post-processing. More specifically, the thermal treatment of $\mathrm{SZ} 2080^{\mathrm{TM}}$ up to $1100{ }^{\circ} \mathrm{C}$ in an air atmosphere results in the organic component of the hybrid materials decomposition and gives pure inorganic metal $(\mathrm{Zr})$ and semimetal $(\mathrm{Si})$ oxides structures with properties close to glass. As an added bonus, the $\mathrm{SZ} 2080^{\mathrm{TM}}$ material loses $28 \%$ of its weight, while a substantial downscaling of a structure reduces it by up to $21 \%$ of the initial size in the $2 \mathrm{D}$ line case and $60 \%$ in the $3 \mathrm{D}$ case $[8,18]$.

This indicates that the obtained inorganic structures become denser compared to the original polymeric structures. The shrinkage is also completely isotropic in all directions, making it very predictable. In addition to shrinkage, densification and demonstrated transparency, high-temperature exposure to SZ2080 ${ }^{\mathrm{TM}}$ derivatives provides resistance to aggressive environmental conditions, such as: chemicals (acids and bases, for instance: Piranha solution), extreme temperatures $\left(-200^{\circ} \mathrm{C}\right.$ to $1100^{\circ} \mathrm{C}$ ) and mechanical effects (rinsing in ultrasonic bath, metal sputtering in vacuum, multiple handling of the sample) [4].

\subsection{Findings in a Wider Context}

The LDW 3D nanolithography enables the exposure of a dose-dependent modification depth (degree of conversion/ polymerization degree), which can offer a 4D option in tuning the $n$ and at the same time requires even more precise adjustment of laser processing parameters as the geometry is not fully compliant with optical density $[29,30]$. It was reported that thermal post-curing can serve as an efficient strategy, eliminating the process parameters' sensitivity in the mechanical properties of two-photon polymerized materials [31]. Therefore, here we see the proposed calcination route as the way to exclude the $n$ variation of the micro-optics ad the conversion to an inorganic substance after the evaporation of organic substances leaves no memory effect of exposure. This is a very important issue being recognized in free-form 3D micro-optics. Furthermore, it allows the extinction of any photo-initiator used during the laser photopolymerization as an organic molecule, which is non-preferable due to its absorbance [32] and yellowing effects [26] - both limiting optical performance of micro-optics. 


\subsection{Benchmarking Achievements}

Finally, we produced benchmarking structures resembling micro-optical components as free-standing, mounted and assembled miniature systems, shown in Figure 5a-d respectively. As the geometry of the manufactured pristine element can be arranged freely to pre-compensate for the calcination induced sintering, it can be simply adjusted for any architecture by including the angle $\alpha$ with respect to the non-shrinking surface of the substrate.

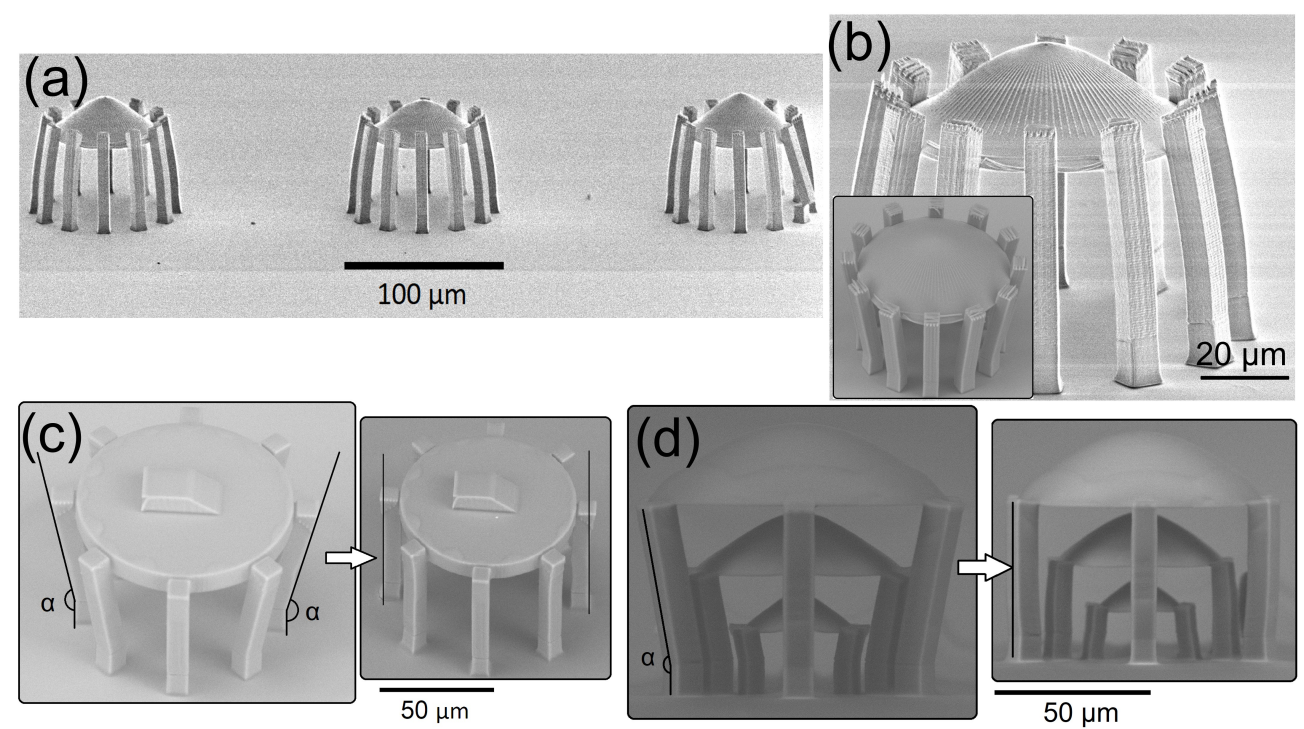

Figure 5. Scanning electron micrographs of a few benchmarking micro-optical components validating the feasibility of the proposed method for the manufacturing of assembled devices: (a) - a row of suspended calcinated free-standing aspheric micro-lenses; (b) closeup of single micro-lens indicating fine features, i.e., periodical grating on the lens surface remains undistorted after heat-treatment, inset - the same lens before calcination; (c) microprism on a pedestal with pre-compensated angle $\alpha=11^{\circ}$ for calcination; (d) - a compound micro-optical component consisting of three stacked microlenses. Micrographs (c,d) are size-adjusted to show the structures dimensions before (left) and after (right) calcination on the same scale. All of the shown demonstrators prove the final free-form geometries are achievable via shrinkage dimensional pre-compensation in pristine material and perfectly arranged architectures after sintering.

Specific different benchmarking micro-optical components were produced using slightly different exposure parameters (adjusted for the specific geometries) and characterized only geometrically (architecture wise, not in the optical performance sense). This was made purely to validate the feasibility of the proposed methods for the manufacturing of non-spherical (i.e., aspherical with concentric grating (Figure 5a,b, flat faced (Figure 5c)) optical surfaces and already assembled devices (Figure 5d).

All flat faced surfaces of the elements were raster printed with typical layer hatching and slicing periods of 250 and $400 \mathrm{~nm}$, respectively. Aspherical surfaces were printed by scanning spiral loops separated by $200 \mathrm{~nm}$ in lateral and $250 \mathrm{~nm}$ in axial directions. In all cases, linear writing velocity was set to $500 \mu \mathrm{m} / \mathrm{s}$ and an intensity of $0.27 \mathrm{TW} / \mathrm{cm}^{2}$ (which in other measures maintains a $\sim 2.5 \mathrm{~nm}$ separation distance between $E=0.3 \mathrm{~nJ}$ femtosecond pulses). A triplet lens, consisting of three co-axially aligned singlet lenses $(96,66$, and $34 \mu \mathrm{m}$ in diameter) were 3D-printed and heat treated in the air atmosphere at $300{ }^{\circ} \mathrm{C}$ for $4 \mathrm{~h}$. After calcination, diameters of the lenses were found to be $77.5,53$ and $27 \mu \mathrm{m}$, respectively, showing uniform down-scaling of the whole compound to a factor of $0.8 \pm 0.006$ of its initial dimensions. In addition, no visible defacement of the triplet alignment was observed. 
All structures were printed on the foldable supports, pre-compensated by inclination angle $\alpha$ such that supports would stand perpendicularly to the substrate after heat treatment. The inclination angle depends on several parameters (namely down-scaling factor, initial diameter and height of the structure) and was calculated to be $\alpha \approx 11^{\circ}$.

\subsection{Future Research Directions}

In regard to space applications, it is a rising interest in both technological light-based solutions (e.g., materials providing resistance to ionization radiations, space-grade optical fibers, etc.) and in light-driven natural phenomena that could be exploited, especially for outer space applications (e.g., solar sails). We anticipate the reported findings to be valuable for advancing this direction forward.

It is worth noting that the developed approach is in principle compatible with applying bio-derived plant-derived resins as organic ingredients of the hybrid photopolymer prior to the calcination, thus evaporating the renewable resources instead of fossil-originating synthetic polymers [33]. Furthermore, the proposed route is compatible with the multiscaling options within various existing and emerging platforms [34]. Namely, fields such as soft-robotics [35], especially light-mediated manipulation of actuators [36], next to flexible electronics [37] enabled by femtosecond LDW technology [38], is expected to benefit from the revealed findings.

\section{Conclusions}

The performed conceptual work was experimentally validated, as glassy 3D microlenses were made, their transparency imaging properties were approved, and the achieved resolving power reached $4.39 \mu \mathrm{m}$. The findings outreach far beyond the carried out experiment as it can be compatible with various laser 3D lithography setups and hybrid materials, both including commercial ones. Overall, it can be summarized to the following essential conclusions:

1. Laser multi-photon 3D nanolithography of hybrid materials in combination with high-temperature calcination is enabling (nano-)additive manufacturing of free-form micro-optics out of transparent and pure inorganic glasses without any fissure of crucial geometrical distortions.

2. The proposed method offers advantage of uniforming the material in respect to the laser lithography 3D structuring and developing process, thus making the $n$ insensitive to the specific exposure conditions by improving its internal homogeneity and surface quality [39].

3. The future work will be targeted for improving the element itself by additionally pre-compensating for the lens shape (it can be made concave initially to balance the volume of the material), optimizing the calcination treatments (taking into account the specific elevation/cooling steps), and modifying the pristine material (some different Si:Zr ratios as well as validating other inorganic ingredients).

4. We anticipate it as a strategy for extending the additive manufacturing of inorganic 3D structures, offering high complexity integrated devices for micro-sensing [40], nano-fluidic [41] and astro-photonic [42] applications.

5. Finally, the developed methodology is offers the production of highly resilient 3D micro-optical components for harsh chemical, mechanical, pressure and temperature variation environments, including a high optical damage threshold.

This pioneering work is creating a new dimension for true 3D and free-form inorganic micro-optics and extending the possibilities of well-established laser multi-photon 3D lithography as mature LDW technology. The calcination process removes the organic photo-initiator and thus provides benefits of keeping the inorganic micro-optics free from absorbing/coloring agents, which could cause loss of light [18] and even induce damage [19]. On the contrary, the LDW 3D nanolithography of glass-ceramics is in principle compatible with the doping of inorganic active compounds preserving their functionality while being embedded in a 3D structure's matrix [43]. Thus, it makes possible selective ma- 
terial removal, optimizing the 3D components targeted for high-duty performance. Further efforts will be invested in quantitative measurement of effective $n$, which we anticipate might additionally depend on specific geometries of the micro-optical elements.

Author Contributions: D.G.-H. and S.V.- experimental modelling, fabrication, calcination, validation and characterization, preparation of manuscript and figures, G.M.-calcination experiments, A.Č.- construction of optical experimental schemes and provision of resources, D.G.- supervision of experiments and investigation methodology, S.Š. — consultation and data curation regarding calcination, S.J.-formal analysis and interpretation of the results, drafting, review and editing, M.M.-conceptualization, project supervision, funding acquisition, drafting, review and editing. All authors have read and agreed to the published version of the manuscript.

Funding: This research received funding from EU Horizon 2020, Research and Innovation program LASERLAB-EUROPE JRA Project No. 871124 (S.V. and M.M.) and D.G. acknowledges the financial support from the European Social Fund (project No 09.3.3-LMT-K712-17-0016) under the grant agreement with the Research Council of Lithuania (LMTLT).

Data Availability Statement: Not applicable.

Acknowledgments: We acknowledge Maria Farsari and Elmina Kabouraki for kindly providing the authors with the SZ2080 $0^{\mathrm{TM}}$ (IESL-FORTH, Heraklion, Greece) hybrid organic-inorganic materials for performing the described experiments. We thank Edvinas Skliutas (VU LRC, Vilnius, Lithuania) for assisting with the high-resolution SEM imaging.

Conflicts of Interest: The authors declare no conflict of interest.

\section{References}

1. Malinauskas, M.; Žukauskas, A.; Hasegawa, S.; Hayasaki, Y.; Mizeikis, V.; Buividas, R.; Juodkazis, S. Ultrafast laser processing of materials: From science to industry. Light Sci. Appl. 2016, 5, e16133. [CrossRef] [PubMed]

2. Thiele, S.; Arzenbacher, K.; Gissibl, T.; Giessen, H.; Herkommer, A.M. 3D-printed eagle eye: Compound microlens system for foveated imaging. Sci. Adv. 2017, 3, 1602655. [CrossRef] [PubMed]

3. Eaton, S.M.; Hadden, J.P.; Bharadwaj, V.; Forneris, J.; Picollo, F.; Bosia, F.; Sotillo, B.; Giakoumaki, A.N.; Jedrkiewicz, O.; Chiappini, A.; et al. Quantum Micro-Nano Devices Fabricated in Diamond by Femtosecond Laser and Ion Irradiation. Adv. Quant. Technol. 2019, 2, 1900006. [CrossRef]

4. Merkininkaite, G.; Aleksandravicius, E.; Malinauskas, M.; Gailevicius, D.; Sakirzanovas, S. Laser Additive Manufacturing of $\mathrm{Si} / \mathrm{ZrO}_{2}$ Tunable Crystalline Phase 3D Nanostructures. Opto-Electr. Adv. 2022, 5, 210077. [CrossRef]

5. Skliutas, E.; Lebedevaite, M.; Kabouraki, E.; Baldacchini, T.; Ostrauskaite, J.; Vamvakaki, M.; Farsari, M.; Juodkazis, S.; Malinauskas, M. Polymerization mechanisms initiated by spatio-temporally confined light. Nanophotonics 2021, 10, 1211-1242. [CrossRef]

6. Bouzin, M.; Zeynali, A.; Marini, M.; Sironi, L.; Scodellaro, R.; D’Alfonso, L.; Collini, M.; Chirico, G. Multiphoton Laser Fabrication of Hybrid Photo-Activable Biomaterials. Sensors 2021, 21, 5891. [CrossRef] [PubMed]

7. Yang, L.; Mayer, F.; Bunz, U.H.F.; Blasco, E.; Wegener, M. Multi-material multi-photon 3D laser micro- and nanoprinting. Light Adv. Manuf. 2021, 2, 1-17. [CrossRef]

8. Gailevičius, D.; Padolskytè, V.; Mikoliūnaitè, L.; Šakirzanovas, S.; Juodkazis, S.; Malinauskas, M. Additive-manufacturing of 3D glass-ceramics down to nanoscale resolution. Nanoscale Horiz. 2019, 4, 647-651. [CrossRef]

9. Bertoncini, A.; Liberale, C. Polarization Micro-Optics: Circular Polarization From a Fresnel Rhomb 3D Printed on an Optical Fiber. Photon. Technol. Lett. 2018, 30, 1882-1885. [CrossRef]

10. Hou, Z.S.; Xiong, X.; Cao, J.J.; Chen, Q.D.; Tian, Z.N.; Ren, X.F.; Sun, H.B. On-Chip Polarization Rotators. Adv. Opt. Mater. 2019, 7, 1900129. [CrossRef]

11. Bertoncini, A.; Liberale, C. 3D printed waveguides based on photonic crystal fiber designs for complex fiber-end photonic devices. Optica 2020, 7, 1487-1494. [CrossRef]

12. Schmid, M.; Sterl, F.; Thiele, S.; Herkommer, A.; Giessen, H. 3D printed hybrid refractive/diffractive achromat and apochromat for the visible wavelength range. Opt. Lett. 2021, 46, 2485-2488. [CrossRef]

13. Varapnickas, S.; Chandran Thodika, S.; Moroté, F.; Juodkazis, S.; Malinauskas, M.; Brasselet, E. Birefringent optical retarders from laser 3D-printed dielectric metasurfaces. Appl. Phys. Lett. 2021, 118, 151104. [CrossRef]

14. Hong, Z.; Ye, P.; Loy, D.A.; Liang, R. Three-dimensional printing of glass micro-optics. Optica 2021, 8, 904-910. [CrossRef]

15. Kotz, F.; Quick, A.S.; Risch, P.; Martin, T.; Hoose, T.; Thiel, M.; Helmer, D.; Rapp, B.E. Two-Photon Polymerization of Nanocomposites for the Fabrication of Transparent Fused Silica Glass Microstructures. Adv. Mater. 2021, 33, 2006341. [CrossRef] 
16. Doualle, T.; André, J.C.; Gallais, L. 3D printing of silica glass through a multiphoton polymerization process. Opt. Lett. 2021, 46, 364-367. [CrossRef]

17. Vyatskikh, A.; Ng, R.C.; Edwards, B.; Briggs, R.M.; Greer, J.R. Additive Manufacturing of High-Refractive-Index, Nanoarchitected Titanium Dioxide for 3D Dielectric Photonic Crystals. Nano Lett. 2020, 20, 3513-3520. [CrossRef]

18. Jonušauskas, L.; Gailevičius, D.; Mikoliūnaitè, L.; Sakalauskas, D.; Šakirzanovas, S.; Juodkazis, S.; Malinauskas, M. Optically Clear and Resilient Free-Form $\mu$-Optics 3D-Printed via Ultrafast Laser Lithography. Materials 2017, 10, 12. [CrossRef] [PubMed]

19. Butkutè, A.; Čekanavičius, L.; Rimšelis, G.; Gailevičius, D.; Mizeikis, V.; Melninkaitis, A.; Baldacchini, T.; Jonušauskas, L.; Malinauskas, M. Optical damage thresholds of microstructures made by laser three-dimensional nanolithography. Opt. Lett. 2020, 45, 13-16. [CrossRef]

20. Kabouraki, E.; Melissinaki, V.; Yadav, A.; Melninkaitis, A.; Tourlouki, K.; Tachtsidis, T.; Kehagias, N.; Barmparis, G.D.; Papazoglou, D.G.; Rafailov, E.; et al. High laser induced damage threshold photoresists for nano-imprint and 3D multi-photon lithography. Nanophotonics 2021, 10, 3759-3768. [CrossRef]

21. Bundy, K.; Westfall, K.; MacDonald, N.; Kupke, R.; Savage, M.; Poppett, C.; Alabi, A.; Becker, G.; Burchett, J.; Capak, P.; et al. FOBOS: A Next-Generation Spectroscopic Facility. BAAS 2019, 51, 7.

22. Smith, D.; Ng, S.; Han, M.; Katkus, T.; Anand, V.; Glazebrook, K.; Juodkazis, S. Imaging with diffractive axicons rapidly milled on sapphire by femtosecond laser ablation. Appl. Phys. B 2021, 127, 154. [CrossRef]

23. Ovsianikov, A.; Viertl, J.; Chichkov, B.; Oubaha, M.; MacCraith, B.; Sakellari, I.; Giakoumaki, A.; Gray, D.; Vamvakaki, M.; Farsari, M.; et al. Ultra-Low Shrinkage Hybrid Photosensitive Material for Two-Photon Polymerization Microfabrication. ACS Nano 2008, 2, 2257-2262. [CrossRef]

24. Jonušauskas, L.; Gailevičius, D.; Rekštytè, S.; Baldacchini, T.; Juodkazis, S.; Malinauskas, M. Mesoscale laser 3D printing. Opt. Express 2019, 27, 15205-15221. [CrossRef]

25. Sharipova, M.I.; Baluyan, T.G.; Abrashitova, K.A.; Kulagin, G.E.; Petrov, A.K.; Chizhov, A.S.; Shatalova, T.B.; Chubich, D.; Kolymagin, D.A.; Vitukhnovsky, A.G.; et al. Effect of pyrolysis on microstructures made of various photoresists by two-photon polymerization: Comparative study. Opt. Mater. Express 2021, 11, 371-384. [CrossRef]

26. Ristok, S.; Thiele, S.; Toulouse, A.; Herkommer, A.M.; Giessen, H. Stitching-free 3D printing of millimeter-sized highly transparent spherical and aspherical optical components. Opt. Mater. Express 2020, 10, 2370-2378. [CrossRef]

27. Schneider, C.A.; Rasband, W.S.; Eliceiri, K.W. NIH Image to ImageJ: 25 years of image analysis. Nat. Methods 2012, 9, 671-675. [CrossRef]

28. Nogami, M. Glass preparation of the $\mathrm{ZrO}_{2}-\mathrm{SiO}_{2}$ system by the sol-gel process from metal alkoxides. J. Non-Crystall. Sol. 1985, 69, 415-423. [CrossRef]

29. Žukauskas, A.; Matulaitienè, I.; Paipulas, D.; Niaura, G.; Malinauskas, M.; Gadonas, R. Tuning the refractive index in 3D direct laser writing lithography: Towards GRIN microoptics. Laser Photon. Rev. 2015, 9, 706-712. [CrossRef]

30. Porte, X.; Dinc, N.U.; Moughames, J.; Panusa, G.; Juliano, C.; Kadic, M.; Moser, C.; Brunner, D.; Psaltis, D. Direct (3+1)D laser writing of graded-index optical elements. Optica 2021, 8, 1281-1287. [CrossRef]

31. Bauer, J.; Izard, A.G.; Zhang, Y.; Baldacchini, T.; Valdevit, L. Thermal post-curing as an efficient strategy to eliminate process parameter sensitivity in the mechanical properties of two-photon polymerized materials. Opt. Express 2020, $28,20362-20371$. [CrossRef]

32. Žukauskas, A.; Batavičiūtė, G.; Ščiuka, M.; Balevičius, Z.; Melninkaitis, A.; Malinauskas, M. Effect of the photoinitiator presence and exposure conditions on laser-induced damage threshold of ORMOSIL (SZ2080). Opt. Mater. 2015, 39, 224-231. [CrossRef]

33. Skliutas, E.; Lebedevaite, M.; Kasetaite, S.; Lileikis, S.; Ostrauskaite, J.; Malinauskas, M. A Bio-Based Resin for a Multi-Scale Optical 3D Printing. Sci. Rep. 2020, 10, 9758. [CrossRef]

34. Amico, C.D.; Martin, G.; Troles, J.; Cheng, G.; Stoian, R. Multiscale Laser Written Photonic Structures in Bulk Chalcogenide Glasses for Infrared Light Transport and Extraction. Photonics 2021, 8, 211.

35. Wallin, T.; Pikul, J.; Shepherd, R. 3D printing of soft robotic systems. Nat. Rev. Mater. 2018, 3, 84-100. [CrossRef]

36. Han, D.D.; Zhang, Y.L.; Ma, J.N.; Liu, Y.Q.; Han, B.; Sun, H.B. Light-Mediated Manufacture and Manipulation of Actuators. Adv. Mater. 2016, 28, 8328-8343. [CrossRef]

37. You, R.; Liu, Y.Q.; Hao, Y.L.; Han, D.D.; Zhang, Y.L.; You, Z. Laser Fabrication of Graphene-Based Flexible Electronics. Adv. Mater. 2019, 32, 1901981. [CrossRef]

38. Liu, Y.Q.; Mao, J.W.; Chen, Z.D.; Han, D.D.; Jiao, Z.Z.; Ma, J.N.; Jiang, H.B.; Yang, H. Three-dimensional micropatterning of graphene by femtosecond laser direct writing technology. Opt. Lett. 2020, 45, 113-116. [CrossRef]

39. Schmid, M.; Ludescher, D.; Giessen, H. Optical properties of photoresists for femtosecond 3D printing: refractive index, extinction, luminescence-dose dependence, aging, heat treatment and comparison between 1-photon and 2-photon exposure. Opt. Mater. Express 2019, 9, 4564-4577. [CrossRef]

40. Tičkūnas, T.; Perrenoud, M.; Butkus, S.; Gadonas, R.; Rekštytė, S.; Malinauskas, M.; Paipulas, D.; Bellouard, Y.; Sirutkaitis, V. Combination of additive and subtractive laser 3D microprocessing in hybrid glass/polymer microsystems for chemical sensing applications. Opt. Express 2017, 25, 26280-26288. [CrossRef] [PubMed]

41. Wang, C.; Yang, L.; Zhang, C.; Rao, S.; Wang, Y.; Wu, S.; Li, J.; Hu, Y.; Wu, D.; Chu, J.; et al. Multilayered skyscraper microchips fabricated by hybrid "all-in-one" femtosecond laser processing. Microsyst. Nanoeng 2019, 5, 17. [CrossRef] 
42. Martinod, M.A.; Norris, B.; Tuthill, P.; Lagadec, T.; Jovanovic, N.; Cvetojevic, N.; Gross, S.; Arriola, A.; Gretzinger, T.; Withford, M.J.; et al. Scalable photonic-based nulling interferometry with the dispersed multi-baseline GLINT instrument. Nat. Commun. 2021, 12, 2465. [CrossRef]

43. Wen, X.; Zhang, B.; Wang, W.; Ye, F.; Yue, S.; Guo, H.; Gao, G.; Zhao, Y.; Fang, Q.; Nguyen, C.; et al. 3D-printed silica with nanoscale resolution. Nat. Mater. 2021, 20, 1506-1511. [CrossRef] 